\title{
Sensing a Planet in Crisis
}

\author{
Jennifer Gabrys
}

Keywords: sensors, media and environment, planetary, pollution, citizen sensing

https://doi.org/10.1525/001c.10036

Wildfires in California contributed to some of the worst air quality in the world during late 2018. The fires were considered to be among the most extreme in California's history and were attributed in part to changes in climate and land use. In the process of burning hundreds of thousands of acres of land, the fires created pollution that led to an air quality emergency. At one point, during mid-November 2018, the media widely reported that cities including San Francisco, Sacramento, and Stockton had higher levels of pollution than Delhi or Beijing (Azad 2018). While varying data sources were referenced to support these claims, the most common source reported was from the PurpleAir sensor map and platform, which produced an animation to demonstrate the elevated levels of particulate matter in California (figure 1) (Jeung 2018). With a worldwide network of around two thousand sensors and growing, PurpleAir provides air quality measurements in locations that might be remote or lacking in air quality infrastructure. What is notable about this network is that it is not the product of governmental intervention but rather is driven by individuals and community groups seeking to monitor environmental pollution.

From London to Delhi, and from San Francisco to Paris, digital media technologies are both monitoring and rewiring environments across diverse participants and actors, devices, and infrastructures. People seeking information on pollution levels often consult an official Air Quality Index (AQI). But, as with PurpleAir, increasing numbers of people are also setting up their own sensors to map and monitor air quality levels. Distributed networks of sensors monitor environmental pollutants and inform responses to rapidly changing environmental conditions. These digital media technologies capture traffic events, industrial activity, crop fires, and construction activity in locations around the world. Citizen scientists and citizen sensors, DIY practitioners, and even local and state governments install these networks and attempt to monitor environments in conditions of pollution, disaster, and

\footnotetext{
* Jennifer Gabrys is Chair in Media, Culture and Environment in the Department of Sociology at the University of Cambridge and honorary visiting professor in the Department of Sociology at Goldsmiths, University of London. She is currently principal investigator on the project AirKit, and she leads the Citizen Sense project, both of which have received funding from the European Research Council. She is the author of Program Earth: Environmental Sensing Technology and the Making of a Computational Planet (University of Minnesota Press, 2016) and Digital Rubbish: A Natural History of Electronics (University of Michigan Press, 2011), and coeditor of Accumulation: The Material Politics of Plastic (Routledge, 2013). Her forthcoming books include How to Do Things with Sensors (University of Minnesota Press, Forerunners series, 2019) and Citizens of Worlds: Open-Air Toolkits for Environmental Struggle. Her work can be found at citizensense.net and jennifergabrys.net.
} 




Figure 1: PurpleAir map animation, Inverse.

Image courtesy of PurpleAir at www.purpleair.com. Available at https://www.inverse.com/article/50925-california-wildfire-air-qualityworst-in-world?jwsource $=\mathrm{cl}$.

environmental change. Citizen sensing is one of many practices situated within the expanding field of media and environment, where diverse ways of monitoring and communicating environmental conditions intersect with media technologies.

These sensors and networks are sensing a planet in crisis. PurpleAir formed as a low-cost and publicly available technology to facilitate the monitoring of wildfires and volcanoes (Shankland 2018). In other words, environmental crisis was the raison d'être for developing the devices and setting up the company. The sensors are meant to be readily available and easy-to-use technologies that can be deployed to monitor and respond to environmental calamities as well as everyday scenarios. Media technologies such as computational sensors and the data they generate produce distinct approaches to environments; they sense a planet in crisis, but they also inform the conditions of the planetary crisis. Citizen sensing technologies and data facilitate practices for tuning into and responding to planetary crises. In addition, citizens and communities become politically and environmentally active in particular ways by virtue of the digital media strategies that citizen sensors and citizen data afford.

The Citizen Sense project that I lead through a research group first located at Goldsmiths, University of London, and now based at the University of Cambridge is one such project. Citizen Sense has investigated the ways in which sensor technologies might be developed and put to work by 


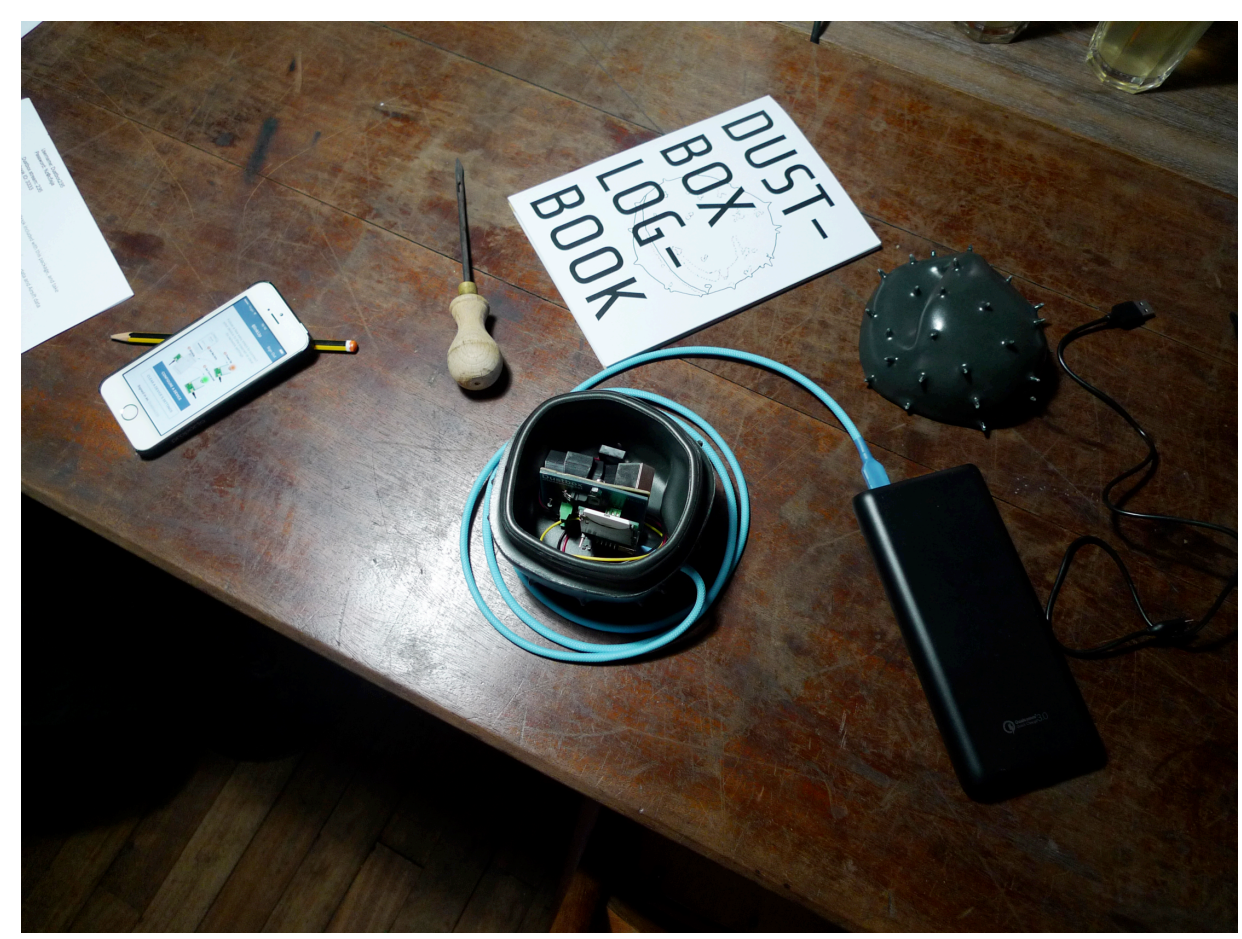

Figure 2: Citizen Sense Dustbox (2016).

Photo by and courtesy of Citizen Sense.

communities to respond to environmental problems. (See http://citizensense.net.) What we have found in the course of this work is that these media-technological practices mobilize distinct formations of citizenship and political engagement. At the same time, these technologies generate distinct ways of noticing and responding to environmental problems-for instance, through the collection of data and presentation of evidence that would attempt to work within and yet also challenge the politics of expertise of environmental management. Most recently, in Southeast London we worked with residents and community groups to install air quality sensor nodes in the form of a particulate matter device we called the "Dustbox" (figure 2). Through collectively analyzing outputs from up to thirty of these devices capturing air pollution levels over the course of ten months, we found that this citizen data offered much different ways of sensing urban environments, which were also aligned with social-justice struggles for "the right to the city" (Gabrys 2019). The relations and practices that sensor technologies in-form are not then simply conditions of control but rather demonstrate distinct political subjects and communities that come into formation at the intersection of media and environment.

The rewiring of environments is then multi-layered. New sensor networks are installed and scale up to infrastructures that concretize as smart environments, and formations of citizenship and political engagement are operationalized through involvement with these devices and infrastructures. In an extended study of such dynamics in my book Program Earth, I have referred to these 
processes as the "becoming environmental of computation," where new environments and digital technologies materialize along with distinct social, political, and cultural conditions (Gabrys 2016). As "citizen" devices, sensors rework the capacities and formations of media and environments. While these are not processes of absolute control or empowerment, these media and environment formations do distinctly situate political agents and ways of being and becoming environmental, here often as a project of gathering data to act on environmental problems. However, as is often the case, citizen data is typically disregarded by policymakers and industry, especially if that data is generated by less privileged community groups and citizen-subjects.

At the same time, technology companies such as Google are deploying Street View cars in cities from San Francisco to London to scan urban streets with "laboratory-grade" sensors installed on the cars, which provide detailed maps of air quality and air pollution data (figure 3). ${ }^{1}$ As environments are increasingly polluted, razed, and plundered, they are also sites of accelerating technologization, where the "technologies of the Fourth Industrial Revolution" are meant to "offer new tools for enabling better stewardship of the Earth" (World Economic Forum 2018). "Our environmental future," in other words, is proposed to be best managed through an array of "innovative data collection and analysis tools such as small satellites; robotic platforms for air, land and water; novel sensors; AI; and genetic sequencing" (World Economic Forum 2018). Planetary stresses, from climate change to biodiversity loss, are to be addressed and mitigated through this "Fourth Industrial Revolution for the Earth" (World Economic Forum 2018), which consists of media technologies that act on and for very particular versions of environments and environmental well-being.

My own work at the intersection of media and environment dates from at least 2002, when I began to research and develop practice-based projects on remote sensing and satellites, sensors and smart dust, wireless technologies, digital cities, and electronic waste. ${ }^{2}$ While the emergence of media and environment as an area of research within media studies might be aligned with earlier developments in media ecology and environment as media infrastructure, it might equally be associated with the increasing and intensifying range of media technologies that are shifting approaches to and understandings of environments.

This assessment of the "state of media and environment" suggests that the current planetary crises of climate change, pollution, biodiversity loss, landuse change, and resource shortages are entangled with the proliferation of technologies that would manage environments and extract resources while

\footnotetext{
1 See Google. This project began by detecting methane from leaking gas pipelines and has now developed to sense urban air pollution. (Google n.d.)

2 Many of the projects can be found at http://jennifergabrys.net.
} 




Figure 3: Google Street View air-pollution sensors.

Image courtesy of Google. Available at https://sustainability.google/projects/airview.

promoting sustainability. Yet in researching and practicing in this area of media and environment, it is worthwhile to question: How do these environmental technologies help to mitigate the escalation of a warming and polluted planet? Or, alternatively, to what extent do they monitor a crisis that they have helped to create? ${ }^{3}$

This view of a planet in crisis as approached through sensors and sensing practices is not the "one world" of Spaceship Earth but rather is composed of multiple sites with disparate and uneven effects, where pollution and climate change impact environments, humans, and nonhumans, with greater or lesser severity in relation to situated conditions. In this sense, one of the most pressing areas for media and environment researchers to address is the ways that media and environment technologies and practices operationalize or impair projects for environmental justice. With a planet in crisis, it becomes necessary to consider alternative ways of "becoming planetary" (Gabrys 2018) and, in so doing, to shift the subjects, relations, politics, and technologies that concresce to build other-less destructive and more just—worlds.

This is an open-access article distributed under the terms of the Creative Commons Attribution 4.0 International License (CCBY-4.0). View this license's legal deed at http://creativecommons.org/licenses/ by/4.0 and legal code at http://creativecommons.org/licenses/by/4.0/legalcode for more information. 


\section{REFERENCES}

Azad, Arman. 2018. "Due to Wildfires, California Now Has the Most Polluted Cities in the World." CNN. November 17, 2018. https://edition.cnn.com/2018/11/16/health/san-franciscowildfires-air-quality-worst-in-world/index.html.

Gabrys, Jennifer. 2014. "Powering the Digital: From Energy Ecologies to Electronic Environmentalism.” In Media and the Ecological Crisis, edited by Richard Maxwell, Jon Raundalen, and Nina Lager Vestberg, 3-18. New York: Routledge.

-C- 2016. Program Earth: Environmental Sensing Technology and the Making of a Computational Planet. Minneapolis: University of Minnesota Press. https://doi.org/10.5749/ minnesota/9780816693122.001.0001.

-_-. 2018. "Becoming Planetary." E-Flux Architecture, October 2018. https://www.e-flux.com/ architecture/accumulation/217051/becoming-planetary.

_-_. 2019. "Data Citizens: How to Reinvent Rights." In Data Politics: Worlds, Subjects, Rights, edited by Didier Bigo, Engin Isin, and Evelyn Ruppert, 248-66. London: Routledge.

https://doi.org/10.4324/9781315167305-13.

Google. n.d. "Mapping the Invisible: Street View Cars Add Air Pollution Sensors.” Accessed September 1, 2019. https://sustainability.google/projects/airview.

Jeung, Tiffany. 2018. "Animation Shows California Air Quality Is Worst in the World during Wildfires.” Inverse, November 16, 2018. https://www.inverse.com/article/50925-californiawildfire-air-quality-worst-in-world?jwsource $=$ cl.

Shankland, Stephen. 2018. "California Fires Boost Interest in PurpleAir's Pollution Sensors." CNET. November 21, 2018. https://www.cnet.com/news/california-fires-boost-interest-inpurpleair-air-pollution-sensors.

World Economic Forum. 2018. “Centre for the Fourth Industrial Revolution Network.” December 2018. http://www3.weforum.org/docs/WEF_C4IR_Network_2018.pdf. 